\title{
Chemistry of medicinal plants as an integral part of ecological education
}

\author{
Tetiana Derkach*, and Hanna Tarasenko \\ Kyiv National University of Technologies and Design, 01011, Kyiv, Ukraine
}

\begin{abstract}
The degree of variability in the composition of herbal medicines was studied on the example of the preparation of St. John's wort from various Ukrainian producers. The $\mathrm{Cu}$ and $\mathrm{Zn}$ contents were the most stable compared to other ( $\mathrm{Fe}, \mathrm{Mn}, \mathrm{Co}, \mathrm{Cr}, \mathrm{Ni}, \mathrm{Pb}, \mathrm{Cd}$ ) microelements among plants of different origins. The content of toxic elements $(\mathrm{Pb}, \mathrm{Cd})$ did not exceed the established standards. Meanwhile, a 2-3-fold concentration difference was observed for hyperforin, an active pharmaceutical ingredient in St. John's wort. Thus, the existing standards do not ensure the stability of the composition of herbal preparations. As a result, the quality of medicinal drugs can be significantly different. The key reason for the variation in plant composition is environmental influence, including anthropogenic factors. Existing training programs for prospective specialists of the pharmaceutical industry do not pay enough attention to the impact of the environment on the quality of herbal raw materials. Necessary changes to the syllabi of relevant disciplines are formulated to eliminate this shortcoming and ensure sustainable development of raw materials sources for the pharmaceutical industry.
\end{abstract}

\section{Introduction}

Medicinal plants have a long millennial history of use. However, even today, they remain an essential part of modern medicine [1]. Many synthesised medicaments were made from plant extracts. By some estimates, about $25 \%$ of medications used worldwide are obtained directly from medicinal plants. Besides, they are used by pharmaceutical companies and in food, confectionery, cosmetics, paints, and varnishes.

Most herbal medicines belong to the group of overthe-counter medication and are consumed by patients in self-medication. There is a widespread misconception among consumers that "natural" always indicates "safe", and the consumption of the natural product does not carry a risk $[2,3]$. However, some medicinal plants are toxic, primarily due to low quality and non-compliance with standards [4]. Besides, some herbal medicines may have serious side effects or be ineffective [5]. For example, herbal remedies are not usually adequate to treat any acute illness [6].

In many cases, herbal medicines can be used to treat the same diseases as synthetic medicaments. However, a significant difference exists between these two categories of drugs. Synthetic medicaments usually contain one active pharmaceutical ingredient (API). Their characteristics, including chemical and elemental composition, are clearly defined. Clinical trials determine safe consumption doses. The ingress of foreign organic or elemental impurities into the drug is controlled at all pharmaceutical production stages. Unlike synthetic medicaments, each herbal preparation is always a polypharmacy source because it contains a mixture of metals, metalloids and compounds.

Standardisation of plant raw materials and herbal medicines is much more complex and acute than standardisation of synthetic drugs [7,8]. The complexity is caused by the variability of plant raw materials $[9,10]$.

The composition and quality of plants simultaneously depend on several botanical, biological, physical and chemical factors [6]. Botanical factors determine colour, odour, taste, some other characteristics [11]. Their knowledge underlies the primary identification of a plant. Physical factors determine moisture, final ash and extractives and characterise the quality of vegetable raw materials [11]. Biological factors determine the level of contamination by microorganisms, such as bacteria and their spores, mould, yeast, viruses, and others [12, 13]. The intensity of microbiological contamination directly affects the quality and safety of medicinal plants. However, the greatest variety of influencing variables falls into chemical factors, affecting API content and inorganic elements in plants $[14,15]$. The combined effect of organic and inorganic components determines the therapeutic activity and safety of herbal preparations.

Medicinal plants can contain large and variable amounts of organic compounds. Assessment of the quality of medicinal plants is mainly based on the availability and content of the API. Residues of pesticides, fertilisers and mycotoxins endanger the safety of medicinal plants [16].

Medicinal plants always contain elemental impurities. Chemical elements in plants can be divided into essential elements in biochemical processes and some other elements that do not participate in plant vital functions

\footnotetext{
* Corresponding author: derkach.tm@knutd.edu.ua
} 
[17]. Essential elements, in turn, are divided into macroand micronutrients. Macronutrients (N, P, K, Ca, Mg and $\mathrm{S})$ are needed in large quantities for plant growth. Micronutrients are primarily $\mathrm{B}, \mathrm{Cu}, \mathrm{Fe}, \mathrm{Cl}, \mathrm{Mn}, \mathrm{Mo}, \mathrm{Zn}$, and Ni. They are also crucial for plant development but are needed in small quantities. At optimal concentrations, the essential elements are useful while they can become toxic in excess. A plant poorly develops in deficiency of essential elements. In the meanwhile, the content of essential microelements is often not controlled in herbal medicines.

Some other elements (Ba, Be, Sr, Y, V and others) do not contribute to plant development. The role of some elements, e.g. Al and Co, is still being clarified [17]. Nonessential impurities are the product of the interaction of plants with the environment. Both essential and nonessential elements can be toxic to the consumers of herbal medicines. Some non-essential metals ( $\mathrm{As}, \mathrm{Cd}, \mathrm{Pb}$ and $\mathrm{Hg}$ ) are very harmful [18, 19]. Contamination with impurity elements can occur at all stages - from growing and collecting raw materials to herbal medicine production [20]. Monitoring toxic ingredients is vital to prevent the human body poisoning through their consumption of herbal medicines.

The concentration of elemental impurities varies widely depending on various botanical, geological and environmental factors. Plants simultaneously receive chemicals from the environment in several ways [21]. The most natural way is exchanging the plant and surrounding soil and water [17]. However, different plants have different attitudes to the accumulation of other elements; i. e. show different bioaccumulation rates. For example, some plants, known as excluders, maintain metal concentrations at constant and low levels over a wide range of soil composition. Other plants, known as accumulators, show the effect of hyperaccumulation of cadmium or other ions $[18,19]$. However, even the high content of toxic elements can sometimes not affect plant appearance [22]. Therefore, contaminated and clean plants can be difficult or impossible to distinguish.

Many works were devoted to the study of plants collected in different geographical locations. Such results allow us to study the cumulative effect of local diversity of plant species within one botanical genus [23, 24] and also the impact on the environment $[25,26]$. For example, pollution by heavy metals of small Ukrainian rivers was studied in $[27,28]$ from the viewpoint of polluted waters influence on the local plant growth.

Pollution of air, soil, and water by human economic activity products has a critical impact on plant development. The effect of agriculture increases the concentration of pesticides and other chemicals [29]. Metallurgy, mining and chemical industries place a heavy burden on the environment. Their activity can lead to emissions of a range of metals, which in turn, enter the plant tissue [30, 31]. Transport, railways and highways with heavy traffic are also essential sources of pollution of soils and waters [32].

Most studies usually indicate elevated concentrations of some elements in plants growing in areas with a high anthropogenic load. Sometimes, the opposite picture is observed when natural factors outweigh human-made factors $[33,34]$. In Ukraine, approximately $50 \%$ of the bulk medicinal herb feedstock are cultivated under controlled conditions. The rest belong to wild plants [35]. However, cultivated plants are not undoubtedly cleaner than wild plants in impurities [36].

Botanical and geobiological factors can primarily affect API content and, therefore, the quality of herbal medicines. In contrast, environmental factors affect plant quality and the safety of their use due to possible contamination by hazardous substances and microorganisms. Under such conditions, medicinal plant quality cannot be considered separately from the requirements of cultivation and collection of plants, their chemical composition, which differ between producers. However, only limited general information is indicated by producers on the packaging of medicinal herbs. The attention of herbal medicine producers to quality control of plant raw materials is still insufficient. Meanwhile, the quality of plants is primarily ensured by the stability of the chemical and elemental composition.

Thus, the objective situation requires increased attention to the environmental friendliness of plant raw materials. In the long run, this problem can be solved by strengthening the ecological component and forming the necessary competencies in future pharmacists, pharmaceutical industry technologists and ecologists. Such competencies are developed at the theoretical level in learning environmental, analytical and pharmaceutical chemistry [37, 38, 39]. The discipline "pharmaceutical development" contributes to the formulation and study of existing applied problems. The discipline "pharmaceutical quality system" forms an understanding of the need to acquire new knowledge about plant raw materials and use them to improve the production process continuously.

The work aimed to study the variability of the chemical and elemental composition of medicinal plants in the example of St. John's wort. Particular attention is paid to the impact of environmental conditions of Ukraine and the identification of current problems of obtaining high-quality vegetable raw materials. The results allowed the authors to propose the necessary changes to the curricula of a few chemical and technological disciplines in future pharmacists and pharmaceutical technologists' training. The proposed changes aim to strengthen the ecological component of education to ensure the pharmaceutical industry's sustainable development.

\section{Experimental}

\subsection{Sample preparation}

The chemical and elemental composition variability was studied using the medicinal plant Hypericum perforatum L., known as St. John's wort (SJW), and purchased in pharmacies in Kyiv. Three well-known Ukrainian companies specialising in the manufacture of herbal medicines have been selected as suppliers. All three companies (hereinafter producers 1-3) harvest hyperici herba in the central, eastern and western parts of the 
country, respectively, located at a distance of $400-500 \mathrm{~km}$ from each other.

The elemental composition of similar herbal drugs was studied in $[40,41]$. Comparing the results of current and previous works allowed us to assess the stability of the elemental composition of herbal preparations from different regions of the country. Besides the elemental composition, the content of hyperforin, one of the most important biologically active substances in SJW, was determined in the given work.

Before analysis, the herbs were ground in a high-speed rotary mill to obtain homogeneous samples with a grain diameter of $\leq 1 \mathrm{~mm}$, which were then stored in plastic containers. All chemicals used in sample preparation belonged to the analytical class.

A sample weighing $2 \mathrm{~g}$ was placed in a Teflon reaction crucible to analyse the elemental composition. It was treated with $10 \mathrm{ml}$ of a mixture of $30 \%$ hydrogen peroxide $\left(\mathrm{H}_{2} \mathrm{O}_{2}\right)$ and concentrated $65 \% \mathrm{HNO}_{3}(1: 4, \mathrm{v} / \mathrm{v})$.

The sample decomposition was performed in a microwave system with a closed vessel by the following three-stage regime: $80 \%$ power for $15 \mathrm{~min}, 100 \%$ for 5 min and $80 \%$ power for $20 \mathrm{~min}$. After cooling, the transparent solutions were quantitatively transferred to clean volumetric flasks and diluted to $50 \mathrm{ml}$ with twicedistilled water.

Analysis of the hyperforin content was performed by spectrophotometry. Samples for hyperforin analysis (1.0$3.0 \mathrm{~g}$ of plant powder) were placed in a flask with a section with a capacity of $250 \mathrm{ml} .100 \mathrm{ml}$ of hexane was added; the flask was connected to the reflux condenser and heated in a water bath at a moderate boil of hexane for $30 \mathrm{~min}$. The flask is then cooled. Its content was filtered through a paper filter into a $100 \mathrm{ml}$ volumetric flask. The volume of the solution brought up to the mark with hexane. Transfer $5 \mathrm{ml}$ of the resulting extract to a 25 $\mathrm{ml}$ volumetric flask and dilute to volume with hexane.

\subsection{Instrumentation}

The elemental composition of plants was studied by flame atomic absorption spectroscopy (FAAS). A two-beam spectrometer Solaar S4 AA (Thermo Electron Co., USA) was used in the experiment. Standard conditions in air/acetylene flame, $\mathrm{D}_{2}$ correction and external calibration method were applied. Other details of the experiment, including the spectrometer parameters (wavelengths, operating interval, characteristic concentrations, and the width of the slit), were given elsewhere [40].

Identification and quantification of hyperforin were performed by spectrophotometry following the Pharmacopoeia of Ukraine [42]. This technique outperforms others in terms of simplicity, moderate staffing requirements, speed and cost. The spectrophotometric determination used does not separate the content of different derivatives of hyperforin. All compounds, namely hyperforin, adhyperforin and furohyperforin, exhibit absorption maxima at the same wavelength $(272 \pm 2 \mathrm{~nm})$. For this reason, the total content of all the above compounds was determined and denoted by the term "total hyperforin".
The experiments were performed using a spectrophotometer Optizen POP bio (South Korea). The optical density of the analysed solutions was measured at a wavelength of $272 \mathrm{~nm}$. Quantitative determination was performed using standard solutions. For calculations, the specific absorption of hyperforin was taken to be 8200 . SJW extracts were used to prepare standard solutions. California Gold Nutrition EuroHerbs produced extracts. They were certified by Advanced Botanical Consulting \& Testing, Inc. (a US FDA Registered, Independent, ThirdParty Labs). The concentrations of hyperforin in five reference samples ranged from 0.06 to $0.4 \mathrm{mg} / \mathrm{ml}$.

Three independent samples were examined for each concentration. with different

A calibration graph was plotted to quantify hyperforin in the test samples. Experimental points for optical density in standard samples show high values of the coefficient of determination $\mathrm{R}^{2}\left(\mathrm{R}^{2}>0.98\right)$ with an approximation linear line. Thus, the selected experimental conditions (primarily the range of solution concentrations) provide linearity. Standard samples can quantify hyperforin.

\subsection{Statistical analysis}

Measurements of each sample in FAAS and spectrophotometry measurements were repeated at least three times for further averaging. Both own experimental results and the literature data were analysed by statistical methods using IBM SPSS 20. All data were checked for normal distribution using the Kolmogorov-Smirnov test. The results were then expressed either as means for data with a normal distribution or medians for data with asymmetric distributions. The standard deviations of the mean were calculated when necessary.

\section{Results}

\subsection{Medicinal plants and herbal medicines on the officinal market of Ukraine}

Medicinal plants and herbal medicines are widely represented in the market of Ukraine. As of November 2020, the State Register of Medicinal Products includes 14714 trade names of medicaments [43]. Of this number, 12561 positions belong to medicines of different pharmacotherapeutic groups. The rest 2153 items are medicinal substances.

Of the total number of registered trade names, 1507 (10.24\%) are herbal preparations, comprising 1143 herbal medicines and 364 plant substances. Herbal medicines occupy leading positions among drugs of some therapeutic groups. Figure 1 illustrates the ratio of registered medicines of plant and synthetic origin on the example of five therapeutic groups. According to the international Anatomical Therapeutic Chemical (ATC) classification system, these groups include

1. A03 - means for treating functional gastrointestinal disorders;

2. A05 - means for treating diseases of the liver and biliary tract; 
3. C01A - cardiac glycosides and C01E - other cardiac preparations;

4. G01 - antimicrobial and antiseptic agents used in gynaecology and G02 - other gynaecological agents;

5. R05 - remedies against cough and colds.

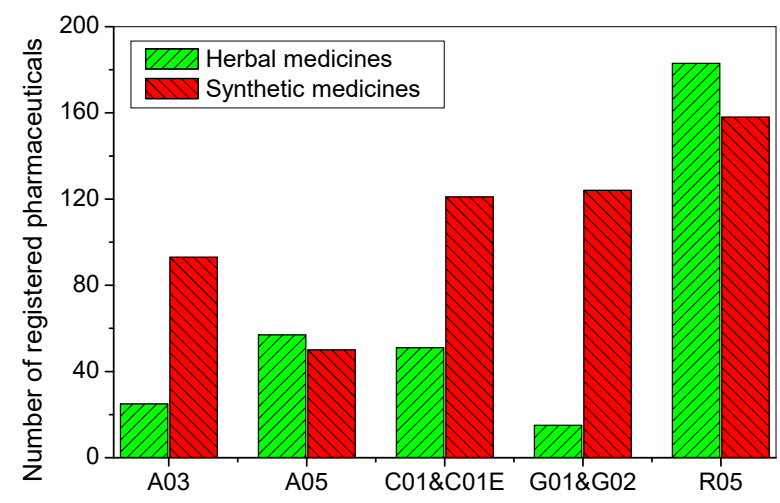

Fig. 1. Number of drugs of plant and synthetic origin for five therapeutic groups registered in Ukraine

The number of herbal medicines in groups R05 and A05 exceeds the number of registered synthetic drugs. Many herbal remedies are used to treat the cardiovascular system's diseases, upper respiratory tract, liver and biliary tract, genitourinary system, etc.

A total of $51(29.65 \%)$ medicinal agents of the 172 registered drugs for the cardiovascular system treatment (groups C01A and C01E) are plant origin drugs. Among the registered drugs of group C01A Cardiac glycosides, all drugs are based on biologically active substances isolated from plant raw materials.

Most herbal medicines are presented on the market in prepared dosage forms - 977 items out of 1143 registered herbal drugs. For example, the range of herbal medicines is dominated by tablets ( $26 \%$ of all herbal medicines), capsules $(11 \%)$, tinctures $(9 \%)$, syrups $(8 \%)$, etc. Of these, 642 positions $(65.71 \%)$ are occupied by domestic drugs and 335 (29.31\%) foreign production.

Only a small part, $166(14.52 \%)$ of the names of finished drugs are presented in the form of officinal preparation (leaves, flowers, grass, fruits, seeds, roots, bark, etc.) of domestic production packaged in packs or packages, of which 32 medicines are teas. The distribution of registered drug substances by dosage forms best illustrates a typical way from herbal raw materials to the pharmaceutical market (Fig. 2).

Most plant raw materials enter the market after significant pre-treatment, including grinding and mixing different parts of the plant (Fig. 2). Then plants turn into powders, extracts, crushed mass, etc. This situation only increases the requirements for the quality of plant raw materials because it is much more difficult to identify plants, assess impurities, etc., at the stage of working with substances.

The analysis shows a rich source of raw materials for the manufacture of medicinal substances in Ukraine. Among 364 substances, 347 (95\%) are substances of Ukrainian origin. A relatively high degree of processing of raw materials in the manufacture of a medicinal substance is striking. The primary forms (leaves, fruits, etc.) account for a little over a third of the available positions. The quality of pharmaceuticals depends on the quality of raw materials. In the next sections, such quality indicators as the stability of the elemental composition and organic compounds' content will be studied using some plant examples.

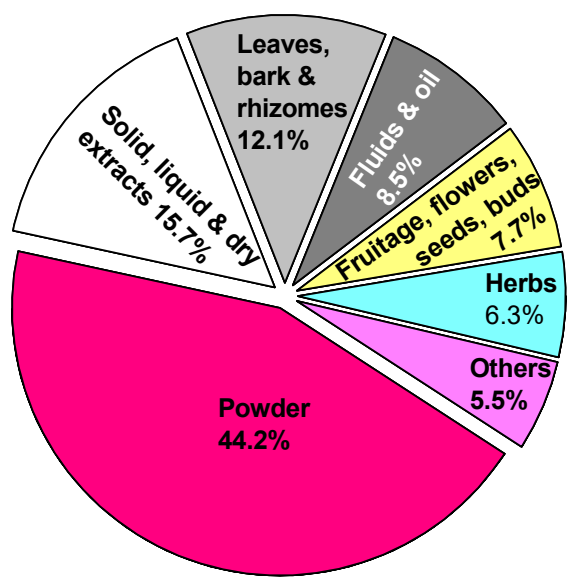

Fig. 2. Structure of registered herbal substances by dosage forms in the market of Ukraine.

\subsection{Elemental composition of medicinal plants}

Variability of concentration of chemical elements is investigated using the herb St. John's wort. The results of our research for SJW samples of different producers were analysed together with literature data. Among various works, only those were selected, where the authors studied the chemical composition of several (at least three) samples of SJW of different origins. SJW specimens purchased at markets or pharmacies (hereinafter named herbs) and representatives of aerial parts of wild plants collected in different geographical locations (shown as plants) are considered.

Due to natural and anthropogenic variability, the chemical composition of SJW of the same botanical species (Hypericum perforatum) significantly differs from each other, even in one study. Table 1 shows the intervals of the existence of chemical elements in SJW, according to various authors.

The values of $R$ were calculated to quantify the width of concentration ranges for different elements. $\mathrm{R}$ is the ratio of maximum-to-minimum concentrations reported in the literature: $\mathrm{R}=\mathrm{C}_{\max } / \mathrm{Cmin}_{\mathrm{min}}$. The more extensive the concentration range, the greater the value of $\mathrm{R}$.

The $\mathrm{R}$ values for $\mathrm{Fe}, \mathrm{Mn}, \mathrm{Cu}, \mathrm{Zn}, \mathrm{Cd}$ and $\mathrm{Pb}$ are illustrated in Fig. 3. The data are presented as histograms $\mathrm{N}(\mathrm{R})$, where $\mathrm{N}-$ is the number of considered published research. The $\mathrm{R}$ values for $\mathrm{Cr}, \mathrm{Ni}$ and $\mathrm{Co}$ are not calculated due to the limited number of non-zero data for these elements.

In the case of copper and zinc, the vast majority of observations demonstrate $\mathrm{R}<5$. The $\mathrm{N}(\mathrm{R})$ distribution corresponds to the Gaussian; the average values of $R_{a v}$ are 4.41 and 4.15 for copper and zinc, respectively.

For iron and manganese, the picture is a little different. Plants with increased Fe content, when $\mathrm{R}$ values vary 
from 20 to 65, were detected in a significant number of observations. In most of the studied plants, $\mathrm{R}$ does not, however, exceed 6. The N(R) for Fe follows Gauss's law, the average value of $R_{a v}=13.05$. The Mn distribution curve is more extended than for Fe; most $\mathrm{R}$ occupies a broad band from 2 to 22 . The distribution of $\mathrm{N}(\mathrm{R})$ significantly deviates from the normal law. For this reason, typical values of $\mathrm{R}$ for $\mathrm{Mn}$ are described by a median rather than an average. The median $\mathrm{R}_{\text {med }}=3.9$.

Table 1. The range of concentrations of some essential and toxic trace elements (in $\mu \mathrm{g} / \mathrm{g}$ of dry weight) in samples of St. John's wort according to results of various authors.

\begin{tabular}{|l|l|l|l|l|l|l|l|l|l|l|l|l|}
\hline Country & Sample & $\begin{array}{l}\text { No of } \\
\text { samples }\end{array}$ & Fe & Mn & Cu & Zn & Co & lr & Ni & Cd & Pb & Source \\
\hline Ukraine & Herbs & 3 & $20,8-60,2$ & $60-145,7$ & $6-12,5$ & $15,4-32,5$ & $0,08-0,35$ & $0,2-0,9$ & $0,8-2,8$ & $0,2-0,9$ & $0,3-0,9$ & current \\
\hline Ukraine & Herbs & 3 & $26,7-55,5$ & $56-137,7$ & $5,0-11,9$ & $16,6-31,4$ & $0,08-0,32$ & $0-0,38$ & & $0,02-0,89$ & $0,32-0,61$ & {$[40]$} \\
\hline Ukraine & Herbs & 4 & $10-64,7$ & $55-120,6$ & $7,5-8,4$ & $17,4-19,5$ & $0,1-0,29$ & $0,73-2,0$ & $1,27-2,04$ & $0,23-0,72$ & $0,13-0,73$ & {$[41]$} \\
\hline Serbia & Herbs & 14 & & $25-226$ & $10,0-17$ & $21-56$ & & & $1,0-8$ & $0,3-3$ & $0,5-3,5$ & {$[44]$} \\
\hline England & Herbs & 22 & $38-760$ & $59,1-261$ & $4,64-120$ & $23-64$ & & $0-1,4$ & $0-5,37$ & $0-1,73$ & & {$[45]$} \\
\hline Bulgaria & Stem & 15 & $25-860$ & $28-109$ & $8,0-25,0$ & & & & & & $3,0-19,0$ & {$[46]$} \\
\hline Turkey & Leaves & 3 & $81,7-85,8$ & $29,8-31,9$ & $0,7-0,79$ & $14-14,5$ & & $0,024-0,033$ & $0,47-0,57$ & $0,48-0,56$ & $0,23-0,24[47]$ \\
\hline Turkey & Plants & 35 & $54-2990$ & $9,1-197,9$ & $1,8-10,1$ & $13-181,6$ & & & & & $12-124,8$ & {$[48]$} \\
\hline Turkey & Plants & 4 & $159-443$ & $25,4-34,7$ & $12,9-27,4$ & $16,8-44$ & $0,2-0,3$ & $1,3-2,3$ & & $0,1-2,8$ & $0,1-1,9$ & {$[49]$} \\
\hline Slovenia & Plants & 8 & $32,2-115$ & $7,8-75,4$ & $6,3-11,7$ & $27-103,4$ & & & & $0,2-4,2$ & $2,1-25,1$ & {$[50]$} \\
\hline Estonia & Plants & 3 & & $31,8-54,4$ & & $29,4-35,5$ & $0,1-0,18$ & $0,12-0,24$ & & & & {$[51]$} \\
\hline Romania & Plants & 14 & $83-288$ & $31-219$ & & $40-96$ & & & $0,5-4,9$ & $0,1-1,5$ & $<0,1-1,7$ & {$[52]$} \\
\hline Bulgaria & Plants & 8 & $40-121$ & $12,0-69$ & $5,6-9,1$ & $21,0-47$ & $0,6-1,8$ & $0,9-6,1$ & $0,7-11,7$ & $0,35-0,9$ & $0,7-1,9$ & {$[53]$} \\
\hline
\end{tabular}

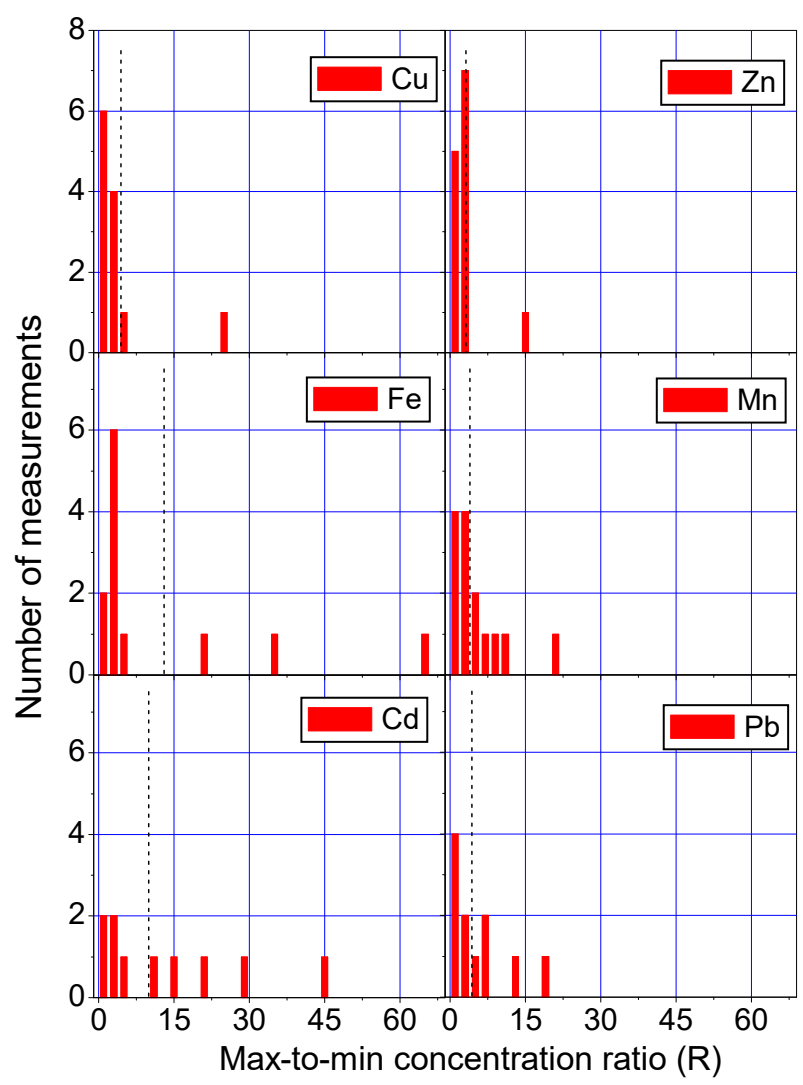

Fig. 3. Histograms illustrate the number of considered research $\mathrm{N}$ as a function of $\mathrm{R}$, the ratio of maximum-to-minimum concentrations of elements in plants. Dotted lines show the mean values for components with a normal distribution ( $\mathrm{Fe}, \mathrm{Cu}, \mathrm{Zn}$ ) and medians for elements with asymmetric distributions (Mn, $\mathrm{Cd}, \mathrm{Pb}$ )

Histograms for toxic impurities, $\mathrm{Cd}$ and $\mathrm{Pb}$, significantly differ from histograms for essential trace elements. Both curves are characterised by an asymmetric, far from a normal distribution. The value of $\mathrm{R}$ for cadmium varies in a wide range from 1.2 to 44 . It is impossible to determine an average $\mathrm{R}$, which is perceived as the most probable $\mathrm{Cd}$ concentration. The median value for cadmium $\mathrm{R}_{\text {med }}=10$. Approximately the same pattern is observed for $\mathrm{Pb}$. However, a significant part of the specimens demonstrates $\mathrm{R}$ values in the range from 1 to 7. The median for lead $\mathrm{R}_{\text {med }}=4.3$.

\subsection{Hyperforin in Saint John's wort}

The average concentrations of hyperforin (Fig. 4a) and some essential elements (Fig. 4b) are shown for herbal samples of different producers.

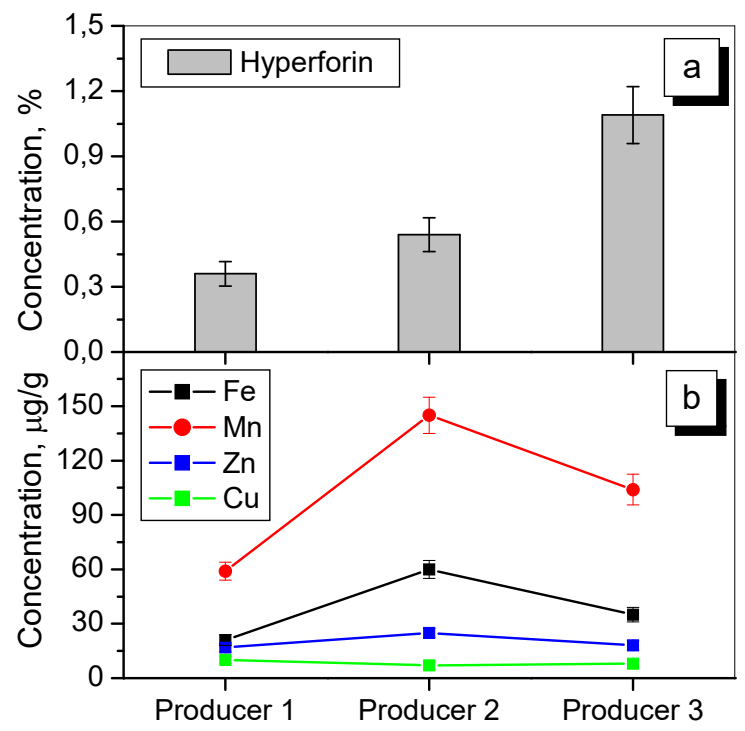

Fig. 4. Measured concentrations of hyperforin (a) and some essential microelements (b) in samples of producers 1-3. 
In producer 3, the hyperforin content is almost three times higher than in specimens of producer 1. The indicators of producer 2 occupy an intermediate position, although still slightly closer to producer 1 .

Figure $4 \mathrm{~b}$ illustrates the detected scatter of concentrations of essential micronutrients in samples from different producers. Compared to others, zinc and copper concentrations show the most stable behaviour. In contrast, the concentrations of manganese and iron vary over a fairly wide range. Thus, the highest determined concentration of manganese in samples of producer 2 is actually 2.5 times higher than the lowest concentration of this element in herba of producer 1. A similar situation is observed for iron, where the maximum concentration (producer 2) is almost five times higher than the minimum concentration (producer 1).

The obtained results do not allow the authors to confirm the conclusions made earlier in [40] on the presence of anticorrelation between the concentrations of iron and manganese. However, similar to [40], samples of St. John's wort from producers 2 and 1 again show the highest and lowest concentrations of manganese and iron, respectively. At the same time, the levels of zinc and copper relatively weakly depend on plant origin.

A clear correlation between the concentration of hyperforin and elemental impurities is also not observed. The highest concentration of hyperforin is detected in samples with medium, although relatively high impurity content. Additional research is needed to formulate sound conclusions.

\section{Discussion}

\subsection{Variability of the composition of medicinal plants}

The origin of the variability of element concentrations will be considered using histograms shown in Fig. 3. As mentioned earlier, the value of the parameter $\mathrm{R}$ for copper mostly varies in a relatively narrow range of 1.1-5.6 and is subject to the normal distribution. It can be assumed that such fluctuations reflect the natural variability of copper concentration.

The effect of natural variability of chemical composition is well known and is inherent in virtually all plants. Native reasons cause it. On the one hand, this phenomenon is due to the biologically determined variability of plants belonging to the same family and genus and different species. On the other hand, the chemical composition variability is determined by the geochemical conditions of their cultivation, such as soil composition, underlying rocks, and natural waters [17]. The study of the causes of variability in plant composition goes far beyond the research topic. It is important to note for our purpose that the chemical composition of medicinal plants can vary widely. Human activity is one of the primary sources of chemical elements, including toxic heavy metals widely used in industrial products and waste, accumulated in plant tissues.

The plant body regulates the required level of copper as an essential trace element. Only one observation [45], covering 22 samples from the studied 136 probes, reports the increase of $\mathrm{R}$ to 25.9. The $\mathrm{Cu}$ concentration in some of these 22 samples can amount to $120 \mu \mathrm{g} / \mathrm{g}$ amid traditional $\mathrm{Cu}$ levels of approximately $5-27 \mu \mathrm{g} / \mathrm{g}$. Most likely, the influence of anthropogenic environmental factors is observed in such cases.

Very similar behaviour is typical for $\mathrm{Zn}$. In 101 cases among 136 studied samples, the $\mathrm{Zn}$ concentration varies in a relatively narrow range of $15-100 \mu \mathrm{g} / \mathrm{g}$. It corresponds to the $\mathrm{R} \div 1.1-3.8$. The increase of $\mathrm{R}$ to 14.1 was detected in work [48] only. Such an increase corresponds to the expansion of the concentration range to $12.9-181.6 \mu \mathrm{g} / \mathrm{g}$. Among 35 samples in [48], the $\mathrm{Zn}$ concentration exceeded $100 \mu \mathrm{g} / \mathrm{g}$ in 7 plants only. The increase in $\mathrm{Zn}$ concentration above $50-100 \mu \mathrm{g} / \mathrm{g}$ is not typical for most observations. The influence of external environmental pollution may take place in these few samples described in [48].

The shape of histograms in Fig. 3 significantly changes with the transition to the other two essential elements, iron and manganese. For iron, the curve $N(R)$ is still subject to the normal distribution in most samples. The parameter $\mathrm{R}$ varies from 1.1 to 5.5 , which corresponds to a concentration range of about $20-80 \mu \mathrm{g} / \mathrm{g}$. Meanwhile, many observations with elevated $\mathrm{R}$ are known from the literature $[45,46,48]$. These papers account for 72 samples from the studied 136 probes. More precisely, the iron content exceeded $80 \mu \mathrm{g} / \mathrm{g}$ in 43 plants $[46,48]$, while the results of individual measurements are not shown in [45]. In all 18 samples reported in [49, 52], the $\mathrm{Fe}$ concentration exceeded $80 \mu \mathrm{g} / \mathrm{g}$ despite the moderate value of $\mathrm{R}$. Totally, high iron content was observed in almost half of the studied samples (at least 61 out of 136).

The $\mathrm{R}$ values typically vary between 1.1 and 10.2 for $\mathrm{Mn}$, which corresponds to a concentration range of 10$150 \mu \mathrm{g} / \mathrm{g}$. An expansion of this interval to 21.7 was observed in [48]. An increase of the Mn concentrations to $260 \mu \mathrm{g} / \mathrm{g}$ was observed in some reports [44, 45, 48, 52]. Besides, the distribution $N(R)$ no longer follows the law of normal distribution.

The most likely explanation for the $\mathrm{Fe}$ and $\mathrm{Mn}$ behaviour seems to be the effect of environmental pollution on the concentrations of these two elements in plant tissues. Iron and manganese are among the most common elements in the earth's crust. Iron is the primary structural material of modern civilisation. The annual steel production is about 1.5 billion tons, tens or hundreds of times higher than the output of any other metals or nonmetals. Manganese is widely used in the metallurgy, production of fertilisers, batteries and accumulators. The systematic processing of manganese wastes is established only in ferrous metallurgy. Waste products with $\mathrm{Mn}$ in all other applications do not have a well-established systemic utilisation. They mostly remain in the environment. Therefore, it is not surprising that these metals are among the primary contaminants of soil and water in Ukraine [25-28].

Cadmium and lead are not essential elements in plants but are very toxic impurities for the human body. It is impossible to determine the typical or most probable values or ranges of $R$. The distribution of $N(R)$ is 
asymmetric. The $\mathrm{R}$ values non-systematically change in a vast range from 1 to 45 for $\mathrm{Cd}$ and vary between 1.1 and 19 for $\mathrm{Pb}$. The $\mathrm{R}$ values for $\mathrm{Pb}$ are very low in some samples. In such probes, the $\mathrm{Pb}$ concentration is a nearby detection limit. The content of $\mathrm{Cd}$ and $\mathrm{Pb}$ measured in plants does not depend on the plant's needs. In turn, it is determined by the degree of contamination of the plant through contacts with the environment $[18,19,24]$.

The hyperforin content was shown to change 2-3 times in samples of different Ukrainian producers (Fig. 4). The quantification of hyperforin is not yet prescribed in Ukraine and EU's Pharmacopoeias but is present in the US Pharmacopoeia. In recent years, it has become increasingly clear that hyperforin is one of the most valuable API of SJW. The detection of hyperforin is also essential for plant identification because it can be considered a promising SJW marker.
The results obtained for hyperforin were compared with the published literature data. The hyperforin concentrations in SJW samples of six Russian producers demonstrated a 2-3-fold variation [54]. The concentration range varied between $0.36 \%$ and $1.16 \%$, which agrees well with the results obtained in this study.

Table 2 also compares the average levels of hyperforin in herbal remedies (SJW extracts) available on the German pharmaceutical market. These results were obtained by recalculating and averaging the primary data from [55]. The direct comparison of the current results with [55] is difficult because herbal samples and extracts were studied in these works, respectively. However, the concentration coefficients stated in [55] allowed us to estimate the range of hyperforin concentrations in the used plant raw materials (Table 2).

Table 2. The average content of hyperforin in medicines of the herb St. John's wort from European producers according to [55] and the estimated range of hyperforin in plant raw materials.

\begin{tabular}{|l|l|l|l|l|}
\hline \multicolumn{1}{|c|}{ Trade name (producer) } & \multicolumn{1}{|c|}{ Dosage form } & $\begin{array}{c}\text { Average hyperforin } \\
\text { in herbal drugs, \% }\end{array}$ & $\begin{array}{c}\text { Concentration } \\
\text { factor * }\end{array}$ & $\begin{array}{l}\text { Estimated range of hyperforin } \\
\text { in medicinal plants, \% }\end{array}$ \\
\hline Jarsin 300 (Lichtwer Pharma) & Sugar-coated tablet 2,49 & $4-7: 1$ & $0,36-0,62$ \\
\hline Neuroplant 300 (Dr Willmar) & Film-coated tablet & 4,14 & $2.5-5: 1$ & $0,83-1,66$ \\
\hline Texx 300 (Krewel-Meuselbach) & Film-coated tablet & 2,5 & $4-7: 1$ & $0,42-0,71$ \\
\hline Felis 425 (Biocur) & Capsule & 2,75 & $3.5-6: 1$ & $0,42-0,71$ \\
\hline Futuran (Madaus) & Capsule & 1,54 & $3.5-6: 1$ & $0,22-0,44$ \\
\hline Helarium 425 (Bionorica) & Capsule & 2,14 & $3.5-6: 1$ & $0,36-0,61$ \\
\hline Laif 600 (Steigerwald) & Film-coated tablet & 1,86 & $5-8: 1$ & $0,23-0,37$ \\
\hline
\end{tabular}

* concentration factor is the ratio of the mass of raw materials (St. John's wort) to the mass of the extract obtained from it

In most cases, this interval coincides with the results of the current work. Also, the results of [55] very well illustrate the high degree of variability in the content of hyperforin. For St. John's wort extract, the hyperforin content should be at least 3\% [56]. Only the preparation Neuroplant 300 met this criterion among all products studied in [55].

\subsection{Approaches to the safe use of herbal medicines}

The obtained results and literature data give a clear idea of a sizeable difference in chemical and elemental composition between plants grown in different conditions. For example, the content of hyperforin in SJW, one of the most significant APIs, varied almost threefold in drugs from different producers. It gives reason to believe that the effectiveness of such medicines will also be different.

The findings of SJW studies mainly apply to other herbal medicines. However, a buyer of such drugs will not receive any information about API's content. The same problem applies to the variability of the elemental composition.

The outer packaging available to the consumer shows only plant name, producer name and address, keeping time, method of application, including features of use and dosage, contraindications, adverse drug reactions, and warnings.
More information can be found in the instructions for medical use of the drug, approved by the Ministry of Health of Ukraine. The main sections of the instruction (for example, the herb SJW) are as follows.

The composition of the drug: the active substance is herba hiperici. The manufacturer is specified. The dosage form is grass. Pieces of leaves, stems, flowers of various shapes and unripe fruits, greenish-yellow, greyish-green, green, dark green, bright yellow or yellow with black dots, greenish-brown, sometimes pink-purple.

The indicated pharmacotherapeutic group and code ATX A01AD11.

St. John's wort contains many compounds: tannins, flavonoids (hyperoside, rutin, quercetin, myricetin, leucoanthocyanidins), saponins, dyes (hypericin, pseudohypericin), essential oil, resinous substances, carotene, and ascorbic acid. This complex of APIs has astringent, anti-inflammatory and some antimicrobial action. It promotes tissue regeneration, has a moderate effect on bile secretion, stimulates gastric secretion and more.

Indications for use and contraindications, appropriate safety measures are also described. As mentioned above, there are no reservations about the variability of chemical and elemental composition.

The studied concentrations do not exceed the permissible limits in the studied Ukrainian samples. However, some literature data indicate the presence of severe contamination of SJW with toxic metals. For example, poisonous cadmium has been determined in 
commercially available medicinal plants or plants in food supplements. Concentrations up to 3 and $1.73 \mu \mathrm{g} / \mathrm{g}$ were found in some SJW samples in [44, 45], respectively. An even higher cadmium level, with $4.2 \mu \mathrm{g} / \mathrm{g}$, was found in wild plants [50]. According to EU guides or US Department of Agriculture standards in medicinal plants and food additives, the maximum permissible concentration of $\mathrm{Cd}$ should not exceed $1 \mu \mathrm{g} / \mathrm{g}$. WHO established even stricter standards for herbal medicines no more than $0.3 \mu \mathrm{g} / \mathrm{g}$ [57].

A similar situation is observed for $\mathrm{Pb}$. Instead of the allowable $2-5 \mu \mathrm{g} / \mathrm{g}$ in plant raw materials, $17 \mu \mathrm{g} / \mathrm{g}$ was observed in SJW stems [46]; $25 \mu \mathrm{g} / \mathrm{g}$ [50] and even $124 \mu \mathrm{g} / \mathrm{g}$ [48] in wild plants.

Exceeding certain limits applies not only to highly toxic impurities but also to some essential trace elements. Unlike the most poisonous metals ( $\mathrm{Pb}, \mathrm{As}, \mathrm{Hg}$ and $\mathrm{Cd}$ ), the toxicity of essential trace elements is much lower. Their permissible doses are not usually regulated in medicinal plants. However, many norms standardise optimal or safe consumption of these metals in functional and supplementary foods, spices, herbal supplements, etc. For example, adequate intake of $\mathrm{Mn}$ is recommended at $1.8-2.3 \mathrm{mg}$ [57]. The minimum risk level or tolerable daily intake is $2-5 \mathrm{mg}$ and $5 \mathrm{mg}$, respectively. Thus, the safe daily consumption of the most Mn-contaminated medicinal plants $[44,45]$ should not exceed $10 \mathrm{~g}$ of herba per day. Allowed consumption with minimal risk is approximately $20 \mathrm{~g}$. Norms for iron are slightly milder than for manganese, but iron content is much higher in some plants. Therefore, according to the standards, the tolerable daily intake of some of the most Fecontaminated plants [48] will be limited to only $5 \mathrm{~g}$ per day.

Among the essential trace elements, chromium is the most toxic. According to the Ministry of Health of Canada, this element is already standardised together with the most toxic metals. The consumption of wild SJW with a Cr content of $6.1 \mu \mathrm{g} / \mathrm{g}$, studied in [53], maybe only about $5 \mathrm{~g}$. The reason is the limitation of adequate intake at 25$35 \mu \mathrm{g}$ [57].

In Ukraine, wild plants account for about $50 \%$ of plant raw material. The reason for collecting wild plants is primarily economic. The current situation will not change quickly, although the general direction of development is to increase the share of cultivated plants in the raw material.

Increased impurities in wild plants are usually associated with human economic activity. Excessive accumulation of toxic contaminants in plants does not always affect their appearance [22]. It creates an additional danger of consuming contaminated plants, which cannot be foreseen only by external inspection.

In addition to the direct effect of accumulated toxic impurities, the mutual influence of elemental composition on API content and vice versa was evidenced [58, 59]. The most straightforward mechanism that explains this effect is the formation of organometallic compounds, which reduce biologically active substances' concentrations.

The problems with unfavourable plant chemistry are part of a broader problem of damaging the ecology of regions. Solving the problem of plant quality cannot be resolved without solving environmental issues. Ecology's impact on the quality of plant raw materials is inherent in Ukraine and other countries. The presence of plant products from different countries on the Ukrainian market only exacerbates this problem. Thus, to ensure the sustainable development of a raw material base of the pharmaceutical industry, the formation of appropriate environmental competencies should be guaranteed in training future specialists in the field.

Standardisation could remove many questions about the stable quality of herbal medicines. However, different countries have different safety standards, and the medicinal plants are qualified according to various algorithms. In a sense, the lack of a single generally accepted method of standardising medicinal plants reflects the problem's complexity. Plants can be considered as "living factories" that produce a variety of chemicals. They include primary metabolites, i.e. those that are important for the growth of the plants themselves (proteins, amino acids, carbohydrates) and secondary metabolites (flavonoids, terpenoids, alkaloids, etc.). All these components work together, providing a synergistic effect in the finished herbal medicine.

All drugs are chemicals, whether they are synthesised in chemical laboratories or plants. Therefore, irrespective of their source, all medicinal chemicals must meet similar quality standards (identity, purity and stability) and ensure clinical efficacy and safety. Reliable and consistent quality is the basis of the efficiency and safety of herbal medicaments.

Due to the complexity and variability of plant products' components, it is not easy to establish a quality control parameter and maintain consistent quality from batch to batch. The variability of the properties of medicinal plants and herbal medicines in the absence of reference standards begins with collecting raw materials. It only increases during the storage and further processing of plant products. Evidence of both benefits and risks is specific to the product tested. It cannot always be extrapolated to other products, as is always the case for synthetic preparations.

The question of the quality of herbal medicines has two sides - external and internal [7]. The first external issue concerns possible contamination (toxic metals, microbes, pesticides, etc.), adulteration and misidentification.

The internal factor is related to the complexity and potential variability of the components of herbs. Implementation and compliance with Good Agricultural and Collection Practice (GACP) and Good Manufacturing Practice (GMP) reduce the risk of external factors adversely affecting herbal medicines. Ideally, standardisation procedures should cover the entire industry, from medicinal plant cultivation to their clinical application. However, there are currently no generally accepted approaches to creating a comprehensive quality assurance system [60]. Producers of herbal remedies apply their own experience and methods to quality assurance.

The influence of internal factors must be regulated through the use of modern analytical and pharmaceutical 
methods. Intensive use of modern instrumental analysis can significantly increase knowledge about the composition of plant raw materials. However, the availability and low price of herbal medicines are some of their main advantages. High cost due to the use of complicated and expensive analytical methods regularly offsets this advantage. The most promising way to improve standardisation procedures is the optimal ratio of technological operations' simplicity and dosed application of modern analytical techniques.

Controlled and stable API content, the absence of contaminants are the main factors that shape herbal medicines' quality. On the one hand, virtually all stages of obtaining raw materials and further processing are regulated in Ukraine by relevant guidelines. On the other hand, API content was shown to vary in the products of different producers. Thus, the existing requirements for medicinal plants do not fully meet modern needs, which are becoming more. The unpredictable variability of the composition combined with the lack of pharmacological and clinical data for most herbal medicines is the main obstacle to the broader use of natural products in medical practice.

\subsection{Environmentally-affected chemistry of medicinal plants in the context of ecological education}

Medicinal plants of Ukraine include about 2215 species, of which $233(10.5 \%)$ are cultivated and introduced species; the rest are wild [61]. A significant amount of medicinal plants is grown in specialised and homestead farms. Among the total number of wild plants (about 1975 species), only 482 species have resource value, forming resource-significant massifs on large areas ( $>1$ ha) or have significant distribution. The studied above SJW has a significant distribution and large reserves within Ukraine.

The official medicine of Ukraine uses about 200 types of medicinal plants. The State Pharmacopoeia of Ukraine [62] includes 198 monographs on plant raw materials and 88 monographs on herbal medicines (extracts, tinctures, etc.).

Among medicinal plants, there are 44 wild species, 32 wild and cultivated species introduced into the culture due to limited reserves of raw materials, 33 cultivated sorts, and 89 imported plants. Increasing demand for herbal medicines necessitates the expansion of production, improved technology, expanded the collection of plant raw materials, and increased its quality requirements.

However, the number of certain types of medicinal plants is decreasing, and the natural reserves of some wild species are entirely or partially depleted. About 200 species are listed in the Red Book of Ukraine, and more than 70 are regionally rare [61]. Many wild medicinal plants have limited resources. More than $50 \%$ of them are significantly distributed but grow scattered or sporadically. Harvesting of such plants in natural places of growth is unprofitable.

The shortage of plant raw materials is due to the ecological load, changing climatic conditions, and anthropogenic factors. In addition to reducing plants' natural habitat, damaged ecology also deteriorates their quality due to contamination with various pollutants. The expansion of the base of raw materials is possible by their introduction into the culture. Therefore, the cultivation of plants essential for the pharmaceutical industry will enhance in the future.

The formation of professional knowledge, skills, and abilities related to medicinal plants is an essential component of training specialists for the pharmaceutical industry. They include understanding the chemical composition of plants, biosynthesis and accumulation of biologically active substances during plant ontogenesis, and quality control methods of plant raw materials.

The formation of the ability to anticipate changes that occur with raw materials under environmental factors is among the essential requirements. These skills are necessary to choose the optimal conditions for cultivation, harvesting, drying and storage, standardisation and quality control methods of plant raw materials and herbal medicines following the requirements of pharmacopoeias and national standards.

The competence that needs to be formed can be called the ecological thinking of a future specialist. It includes the desire to preserve the environment, the ability to act socially responsible and socially conscious, and the ability to assess and ensure the quality of professional work performed.

At present, the existing curricula of some related disciplines are not perfect. The introduction of particular environmentally-oriented educational elements in the programs of disciplines will contribute to the formation of the ability to operate in conditions of use of raw materials, the quality of which depends on the environment.

We propose to do this consistently, starting with the study of analytical chemistry at the bachelor's level and ending with developing particular components for the discipline of "pharmaceutical quality system" within a master's programme (Table 3 ).

Introducing the necessary topics into syllabi and the definition of expected knowledge and learning outcomes will ensure continuity and consistency in industry specialists' training.

The proposed approach allows the graduation of specialists who will meet the requirements for sustainable development of Ukraine in the coming decades. They will be able to predict changes in plant raw materials under the influence of environmental and climatic conditions, respond promptly, and take measures to prevent deterioration in pharmaceutical products' quality. They will also be able to move to models of balanced consumption and production of medicines based on medicinal plant raw materials.

\section{Conclusions}

1. The stability of elemental and chemical compositions of herbal medicines was studied using samples of herba St. John's wort of different origin. Own experiments were conducted using samples of three different Ukrainian producers purchased in pharmacies. 
The measured chemical and elemental compositions of herbs were compared with the literature on SJW herbal preparations and wild plants.

2. Among the trace elements, the concentrations of copper and zinc in plants show the best stability, usually ranging from 10 to $100 \mu \mathrm{g} / \mathrm{g}$. The normal distribution of the sample number vs $\mathrm{Cu}$ and $\mathrm{Zn}$ concentrations and relative stability of the composition suggests that the environmental influence on these elements' content is minimal compared to other elements.

3. In contrast, the concentrations of manganese and iron in St. John's wort vary over a broader range. Many plants demonstrated traditional concentrations range from $10-20$ to $100-150 \mu \mathrm{g} / \mathrm{g}$. In some studies, the content of Fe and $\mathrm{Mn}$ has increased tens or even hundreds of times. Both $\mathrm{Fe}$ and $\mathrm{Mn}$ are essential elements necessary for plant life. However, they are also among the most common metals used in modern civilisation. Therefore, the anthropogenic load on plants seems to be much higher concerning $\mathrm{Mn}$ and Fe compared to other elements. The state of the environment causes significantly higher iron and manganese content in some plants.
4. Usually, the concentrations of other studied essential trace elements, $\mathrm{Ni}, \mathrm{Co}, \mathrm{Cr}$, do not exceed 1$1.5 \mu \mathrm{g} / \mathrm{g}$. Concentrations above $2 \mu \mathrm{g} / \mathrm{g}$ were not found in the studied samples and are also abnormally rare in the literature. The slightest variation in the content of these elements in the soil or water tangibly affects their concentration in plants. This fact complicates understanding the causes of these elements' variability in plant tissues. The detected concentrations of these elements in plants do not exceed the existing norms concerning their content in dietary supplements or herbal preparations.

5. Toxic cadmium and lead are not vital elements in plants. Therefore, their content depends entirely on the environment of plant growth. The large concentration interval observed in various works reflects the environmental influence on the content of hazardous impurities. Among the herbal drugs, the $\mathrm{Pb}$ and $\mathrm{Cd}$ content met the existing standards in all studied cases. Some samples collected in the wild exhibited dangerously high levels of these elements.

Table 3. Proposed changes in the content of educational components for the formation of environmental thinking of bachelor and master students of pharmacy.

\begin{tabular}{|c|c|c|}
\hline Name the topics & Expected knowledge & Learning outcomes \\
\hline \multicolumn{3}{|c|}{ Bachelor's degree; Educational component: analytical chemistry } \\
\hline $\begin{array}{l}\text { Sampling and sample preparation. } \\
\text { Classical and instrumental analysis. } \\
\text { Processing of experimental data. }\end{array}$ & \begin{tabular}{|l|} 
Methods of sampling and sample \\
preparation of vegetable raw materials. \\
Physicochemical methods of analysis. \\
Quantitative characteristics of the \\
quality of vegetable raw materials. \\
Statistical methods of data analysis. \\
\end{tabular} & $\begin{array}{l}\text { Ability to: } \\
\text { - choose the methods of analysis and sample } \\
\text { preparation adequate to the practical tasks of } \\
\text { determining the content of elements in } \\
\text { medicinal raw materials; } \\
\text { - critically evaluate and analyse the results. }\end{array}$ \\
\hline \multicolumn{3}{|c|}{ Bachelor's degree; Educational component: pharmaceutical chemistry } \\
\hline $\begin{array}{l}\text { Pharmacopoeial methods for the } \\
\text { quantitative determination of toxic and } \\
\text { heavy metals in plant raw materials. }\end{array}$ & $\begin{array}{l}\text { Requirements for the quality of } \\
\text { medicinal plant raw materials. } \\
\text { Pharmacopoeial methods of quantitative } \\
\text { determination. } \\
\quad \text { Actual intervals of the content of } \\
\text { essential elements and impurities in } \\
\text { comparison with their admissible } \\
\text { concentrations. }\end{array}$ & \multirow{3}{*}{$\begin{array}{l}\text { Skills to: } \\
\text { - use methods of State Pharmacopoeia of } \\
\text { Ukraine to analyse the quality of raw } \\
\text { materials; } \\
\text { - anticipate possible complications in } \\
\text { developing herbal remedies; } \\
\text { - apply modern instrumental methods to } \\
\text { determine the characteristics of plant raw } \\
\text { materials. }\end{array}$} \\
\hline Master's degree; Educational cor & mponent: pharmaceutical development & \\
\hline $\begin{array}{l}\text { System for monitoring the } \\
\text { technological process and product } \\
\text { quality. } \\
\text { Pharmaceutical development of } \\
\text { technological process and strategy of } \\
\text { drug control. }\end{array}$ & $\begin{array}{l}\text { Components and content of the stages } \\
\text { of taking medicinal plant raw materials. } \\
\text { Methods of quality control of } \\
\text { medicinal plant raw materials, intermediate } \\
\text { products and finished herbal medicines. }\end{array}$ & \\
\hline \multicolumn{3}{|c|}{ Master's degree; Educational component: pharmaceutical quality system } \\
\hline $\begin{array}{l}\text { Application of the pharmaceutical } \\
\text { quality system during the life cycle of } \\
\text { the drug. } \\
\text { Risk management for quality. }\end{array}$ & $\begin{array}{l}\text { The system of organisation of quality } \\
\text { control of technological process and } \\
\text { products. } \\
\text { Variable composition of medicinal } \\
\text { plant raw materials as a risk factor in the } \\
\text { production of herbal medicines. }\end{array}$ & $\begin{array}{l}\text { Ability to: } \\
\text { - develop a quality system for a } \\
\text { pharmaceutical company that produces } \\
\text { herbal medicines; } \\
\text { - manage the risks that may arise due to } \\
\text { environmental impact on raw materials' } \\
\text { quality; } \\
\text { - gain new knowledge to improve herbal } \\
\text { medicine production continuously. }\end{array}$ \\
\hline
\end{tabular}


6. The content of hyperforin varies between 0.35 and $1.15 \%$. The measured API concentration is almost three times higher in the samples of producer 3 compared to producer 1 . There was found no clear correlation between the elemental composition and API content.

7. The existing standards governing collecting and processing herbal raw materials and manufacturing herbal medicines do not fully ensure the composition's stability and, therefore, herbal medicines' effectiveness. Accordingly, the environmental impact on the quality of plant raw materials needs increased attention in a narrow sense. In a broad sense, improving environmental knowledge is necessary among specialists involved in herbal medicines and other herbal preparations.

8 . The problem can be solved by forming the required competencies in the training of prospective pharmacists and technologists of industrial pharmacy. Necessary changes to the syllabi of some fundamental (analytical and pharmaceutical chemistry) and technological (pharmaceutical development and pharmaceutical quality system) disciplines are proposed to ensure the pharmaceutical industry's sustainable development.

\section{References}

1. M. Fitzgerald, M. Heinrich, A. Booker, Medicinal Plant Analysis: A Historical and Regional Discussion of Emergent Complex Techniques. Front. Pharmacol. 10, 1480 (2020). doi:10.3389/fphar.2019.01480

2. M. Heinrich, Quality and safety of herbal medical products: regulation and the need for quality assurance along the value chains. Brit. J. Clin. Pharmacol. 80(1), 62-66 (2015). doi:10.1111/bcp.12586

3. A.A. Izzo, E. Ernst, Interactions Between Herbal Medicines and Prescribed Drugs. Drugs. 61, 21632175 (2001). doi:10.2165/00003495-20016115000002

4. C.A. Ezeabara, O. Ogochukwu, N. Emeka, C.U. Okeke, E.I. Mbaekwe, Heavy Metal Contamination of Herbal Drugs: Implication for Human Health-A Review. Int. J. Tropic. Dis. \& Health. 4(10), 1044-1058 (2014).

5. Sarojini K, L. Arivarasu, Smiline Girija A S, Herbal formulation: Review of efficacy, safety, and regulations. Int. J. Res. Pharmac. Sci. 11(s.3), 15061510 (2020). doi:10.26452/ijrps.v11iSPL3.3467

6. K. Sahil, B. Sudeep, M. Akanksha, Standardisation of medicinal plant materials. Int. J. Res. Ayurveda Pharm. 2(4), 1100-1109 (2011).

7. D. Ghosh, Quality issues of herbal medicines: internal and external factors. Int. J. Complement. Alt. Med. 11(1), 67-69 (2018).

8. R. Shulammithi, M. Sharanya, R. Tejaswini, M. Kiranmai, Standardization and quality evaluation of herbal drugs. J. Pharm. Biol. Sci. 11(5), 89-100 (2016). doi:10.9790/3008-11050189100
9. F. Scotti, K. Löbel, A. Booker, M. Heinrich, St. John's Wort (Hypericum perforatum) Products - How Variable Is the Primary Material? Front. Plant Sci. 9, 1973 (2019). doi:10.3389/fpls.2018.01973

10. A. Booker, A. Agapouda, D.A. Frommenwiler, F. Scotti, E. Reich, M. Heinrich, St John's wort (Hypericum perforatum) products - an assessment of their authenticity and quality. Phytomedicine. 40, 158-164 (2018). doi:10.1016/j.phymed.2017.12.012

11. D. Kaushik, M.K. Pandey, A. Sharma, Current issues in Authentication and Quality control of Natural Products. Res. Plant Biol. 4(5), 57-64 (2014).

12. W. Kneifel, E. Czech, B. Kop, Microbial Contamination of Medicinal Plants - A Review. Planta Med. 68(1), 5-15 (2002). doi:10.1055/s-2002-20060

13. S.-D. Lee, I.-S. Yu, K. Jung, Y.-S. Kim, Incidence and Level of Aflatoxins Contamination in Medicinal Plants in Korea. Mycobiology. 42(4), 339-345 (2014).

14. S. Kohzadi, B. Shahmoradi, E. Ghaderi, H. Loqmani, A. Maleki, Concentration, Source, and Potential Human Health Risk of Heavy Metals in the Commonly Consumed Medicinal Plants. Biol. Trace Elem. Res. 187, 41-50 (2019). doi:10.1007/s12011018-1357-3

15. E Sarrou, L.-P. Giassafaki, D. Masuero, D. Perenzoni, I.S. Vizirianakis, M. Irakli, P. Chatzopoulou, S. Martens, Metabolomics assisted fingerprint of Hypericum perforatum chemotypes and assessment of their cytotoxic activity. Food Chem. Toxicol. 114, 325-333 (2018). doi:10.1016/j.fct.2018.02.057

16. I. Ałtyn, M. Twarużek, Mycotoxin Contamination Concerns of Herbs and Medicinal Plants. Toxins. 12, 182 (2020). doi:10.3390/toxins12030182

17. A. Kabata-Pendias, Trace Elements in Soils and Plants, 4th edn. (CRC Press, Boca Raton, Fl, USA, 2011).

18. R. Chizzola, Metallic mineral elements and heavy metals in medical plants. Med. Aromat. Plant Sci. Biotechnol. 6, 39-53 (2012).

19. C. Locatelli, D. Melucci, M. Locatelli, Toxic metals in herbal medicines. A review. Curr. Bioact. Compd. 10, 181-188 (2014).

20. G. Thamkaew, I. Sjöholm, F.G. Galindo, A review of drying methods for improving the quality of dried herbs. Crit. Rev. Food Sci. Nutr. 19, 1-24 (2020). doi:10.1080/10408398.2020.1765309

21. T. Derkach, V. Khomenko, Elemental composition of the medicinal plants Hypericum perforatum, Urtica dioica and Matricaria chamomilla grown in Ukraine: A comparative study. Pharmacogn. J. 10(3), 486-491 (2018). doi:10.5530/pj.2018.3.80 
22. V.M. Shchukin, N.E. Kuz'mina, Yu.N. Shvetsova, A.I. Lutseva, Comparative Analysis of Heavy Metal and Arsenic Content in Various Herbal Dosage Forms Marketed in Russia. Bull. Sci. Centre Expert Eval. Med. Prod. 10(1), 41-50 (2020). doi:10.30895/19912919-2020-10-1-41-50

23. P. Konieczynski, A. Viapiana, R. Lysiuk, M. Wesolowski, Chemical Composition of Selected Commercial Herbal Remedies in Relation to Geographical Origin and Inter-Species Diversity. Biol. Trace Elem. Res. 182, 169-177 (2018). doi:10.1007/s12011-017-1078-z

24. Kalpana P, K. Balasubramanian, R.A. Kalaivani, Evaluation of Heavy Metals in Selected Medicinal Plants and their Corresponding Soils collected from Environmentally Diverse Locations of India. Res. J. Pharm. and Technol. 11(8), 3489-3493 (2018). doi:10.5958/0974-360X.2018.00645.5

25. N.M. Tsvetkova, Y.O. Tagunova, Geochemical barriers of manganese distribution in edaphotopes of Dnieper Prysamarye. Vìsn. Dnìpropetr. Unìv. Ser. Bìol. Ekol. 23(1), 3-9 (2015). doi:10.15421/011501

26. G.A. Zaitsev, O.A. Dubrovina, R.I. Shainurov, Iron and manganese migration in "soil-plant" system in Scots pine stands in conditions of contamination by the steel plant's emissions. Sci. Rep. 10, 11025 (2020). doi:10.1038/s41598-020-68114-y

27. A. Yatsyk, I. Yatsyk, I. Hopchak, T. Basiuk, Assessment of the ecological status of the surface waters of small rivers of the Western Bug (Zakhidnyi Buh) river basin on the degree of pollution (on an example of the Gapa river). Bull. Agricult. Sci. 98(1), 75-80 (2020). doi:10.31073/agrovisnyk202001-11

28. O. Prokopchuk, V. Hrubinko, Heavy metals in the small rivers of Ternopil region under different types of anthropogenic pressure. Vìsn. Dnìpropetr. Unìv. Ser. Bìol. Ekol. 24(1), 173-181 (2016). doi:10.15421/011621 (in Ukrainian)

29. N.S. Shaban, Kh.A. Abdou, N.El-H.Y. Hassan, Impact of toxic heavy metals and pesticide residues in herbal products. Beni-Suef Univ. J. Bas. Appl. Sci. 5, 102-106 (2016). doi:10.1016/j.bjbas.2015.10.001

30. A. Stanojković-Sebić, J. Maksimović, Z. Dinić, D. Poštić, R. Iličić, A Stanojković, R Pivić, Microelements and Heavy Metals Content in Frequently Utilised Medicinal Plants Collected from the Power Plant Area. Natur. Product Commun. 12(2), 185-188 (2017).

31. C. Roba, C. Rosu, I. Pistea, C. Baciu, D. Costin, A. Ozunu, Transfer of heavy metals from soil to vegetables in a mining/smelting influenced area (Baia Mare - Ferneziu, Romania). J. Environ. Protect. Ecol. 16(3), 891-898 (2015).

32. V.V. Gupal, I.R. Chornavska, The content of heavy metals in soils of protective forest plantations of railway territories. Bull. Poltava State Agrar. Acad. 4, 123-130 (2018). doi:10.31210/visnyk2018.04.18

33. S. Jaison, T. Muthukumar, Chromium Accumulation in Medicinal Plants Growing Naturally on Tannery Contaminated and Non-contaminated Soils. Biol. Trace Elem. Res. 175, 223-235 (2017). doi:10.1007/s12011-016-0740-1

34. A. Splodytel, Landscape and geochemical assessment of ecological condition of environmental protection territories. Visn. V.N. Karazin Kharkiv Nat. Univ. Ser. Geol. Geogr. Ecol. 51, 234-242 (2020). doi:10.26565/2410-7360-2019-51-17

35. M. Kharytonov, M. Babenko, O. Velychko, G. Pardini, Prospects of medicinal herbs management in reclaimed mine lands of Ukraine. Ukr. J. Ecol. 8(1), 527-532 (2018). doi:10.15421/2018 245

36. A. Rehman, H. Ullah, R. U. Khan, I. Ahmad, Population based study of heavy metals in medicinal plant, Capparis Decidua. Int. J. Pharm. Pharmac. Sci. 4, Suppl 1 108-113 (2013).

37. M. Kolchanova, T. Derkach, T. Starova, Conditions for creating a balance between learning styles on the example of the material of the discipline ecological Chemistry and Environmental Monitoring. E3S Web of Conferences, 166, 10028 (2020). doi:10.1051/e3sconf/202016610028

38. M. Skyba, The appliance of the case method to produce constructive and projective ecologicalpedagogical activity competences. Pedagogical sci.: theory, history, innovative technol. 4(58) 354-362 (2016). (in Ukrainian)

39. M. Bilianska, O. Yaroshenko, Ability to foster schoolchildren's ecological literacy as a result of prospective biology teachers' professional training. Probl. Educ. in 21st Cent. 78(6), 907-919 (2020). doi:10.33225/pec/20.78.907

40. T.M. Derkach, V.G. Khomenko, Essential and toxic microelements in the medicinal remedy Hyperichi herba by different producers. Res. J. Pharm. and Technol. 11(2), 466-474 (2018). doi:10.5958/0974360X.2018.00086.0

41. T.M. Derkach, O.O. Starikova, Variation of chemical composition of medicinal herbs of different producers. J. Chem. and Technol. 27(1), 79-91 (2019). doi: $10.15421 / 091909$

42. State Pharmacopoeia of Ukraine, vol. 1, 2nd edn. (Ukrainian Scientific Pharmacopoeial Center for Quality of Medicines, Kharkiv, 2015) p. 76.

43. State Register of Medicinal Products. Information base (Ministry of Health of Ukraine, Kyiv, 2020), http://www.drlz.com.ua. Accessed 15 December 2020 (in Ukrainian)

44. D. Radanovic, S. Antic-Mladenovic, M. Jakovljevic, Influence of some soil characteristics on heavy metal 
content in Hypericum perforatum L. and Achillea millefolium L. Acta Horticul. 576, 295-301 (2002). doi:10.17660/actahortic.2002.576.44

45. J.D. Owen, S.B. Kirton, S.J. Evans, J.L. Stair, Elemental fingerprinting of Hypericum perforatum (St John's Wort) herb and preparations using ICP-OES and chemometrics. J. Pharm. Biomed. Anal. 125, 1521 (2016). doi:10.1016/j.jpba.2016.02.054

46. E.L. Nikolova, R.D. Valcheva, Ch.V. Angelov, Essential and toxic element concentrations in medical herbs from Rila and Pirin (Bulgaria) measured using Energy Dispersive X-ray Fluorescence (EDXRF) Analysis. Acta Zool. Bulg. 11, 163-167 (2018).

47. I.I. Ozyigit, B. Yalcin, S. Turan, I.A. Saracoglu, S. Karadeniz, IE Yalcin, G. Demir, Investigation of heavy metal level and mineral nutrient status in widely used medicinal plants' leaves in Turkey: Insights into health implications. Biol. Trace Elem. Res. 182, 387406 (2018). doi:10.1007/s12011-017-1070-7

48. A.K. Ayan, R. Kizilkaya, C. Cirak, K. Kevseroglu, Heavy metal contents of St. John's wort (Hypericum perforatum L.) growing in northern Turkey. J. Plant Sci. 1(3), 182-186 doi:10.3923/jps.2006.182.186

49. N. Okut, Heavy Metal Contents in Selected Medicinal Plants of Van-Turkey. J. Inst. Sci. Technol. 9(1), 533544 (2019). doi:10.21597/jist.491129

50. N.K, Glavač, S. Djogo, S. Ražić, S. Kreft, M. Veber, Accumulation of heavy metals from soil in medicinal plants. Arch. Industry. Hygiene Toxicol. 68(3), 236244 (2017). doi:10.1515/aiht-2017-68-2990

51. K. Helmja, M. Vaher, T. Püssa, A. Orav, A. Viitak, T. Levandi, M. Kaljurand, Variation in the composition of the essential oils, phenolic compounds and mineral elements of Hypericum perforatum L. growing in Estonia. Natur. Product Res. 25(5), 496510 (2011). doi:10.1080/14786411003792165

52. T. Jurca, E. Marian, L. Vicas, D. Gatea, Simultaneous determination of metals in Hypericum perforatum $\mathrm{L}$. by ICP-OES. Rev. Chimie (Bucharest). 62(12), 11541156 (2011).

53. D. Pavlova, I. Karadjova, I. Krasteva, Essential and toxic element content in Hypericum perforatum. Austral. J. Botany. 63(2), 152-158 (2015). doi:10.1071/BT142601

54. V.V. Milevskaya, Determination of biologically active substances in medicinal herbal raw materials of anti-depressant and anti-inflammatory effect. Dissertation, Kuban State University, 2017. 55. M. Wurglics, K. Westerhoff, A. Kaunzinger, A. Wilke, A. Baumeister, J. Dressman, M. SchubertZsilavecz, Comparison of German St. John's Wort products according to hyperforin and total hypericin content. J. Amer. Pharmac. Assoc. 41(4), 560-566 (2001). doi:10.1016/S1086-5802(16)31280-3
56. A. Agapouda, A. Booker, T. Kiss, J. Hohmann, M. Heinrich, D. Csupor, Quality control of Hypericum perforatum L. analytical challenges and recent progress. J. Pharm. Pharmacol. 71, 15-37 (2019). doi:10.1111/jphp.12711

57. O.P. Baula, T.M. Derkach, Control of elemental impurities in herbal medicines. Farmatsevtychnyi Zhurnal. No3-4 43-52 (2017). (in Ukrainian)

58. D.A. Kostic, J.M. Velickovic, S.S. Mitic, M.N. Mitic, S.S. Randjelovic, B.B. Arsic, A.N. Pavlovic, Correlation among phenolic, toxic metals and antioxidant activity of the extracts of plant species from Southeast Serbia. Bull. Chem. Soc. Ethiopia. 27(2), 1-10 (2013). doi:10.4314/bcse.v27i2.2

59. P. Konieczynski, A. Arceusz, M. Wesolowski, Essential Elements and Their Relations to Phenolic Compounds in Infusions of Medicinal Plants Acquired from Different European Regions. Biol. Trace Elem. Res. 170, 466-475 (2016). doi:10.1007/s12011-0150481-6

60. O.P. Baula, T.M. Derkach, Quality assurance of herbal medicinal products: status and prospects. Pharmaceutical Review. No2, 79-86 (2017). doi:10.11603/2312-0967.2017.2.7816 (in Ukrainian)

61. V.M. Minarchenko, Resource science. Medicinal plants (Fitosotsiocenter, Kyiv, 2014) (in Ukrainian)

62. State Pharmacopeia of Ukraine (Ukrainian Scientific Pharmacopoeial Center for Quality of Medicines, Kharkiv, 2020), http://sphu.org/en/ukrainianpharmacopoeia. Accessed 21 December 2020 (in Ukrainian) 